\title{
Molecular characterization of Leishmania spp. in reservoir hosts in endemic foci of zoonotic cutaneous leishmaniasis in Iran
}

\author{
Mohammad Akhoundi ${ }^{1,2}$, Mehdi Mohebali ${ }^{3}$, Mina Asadi ${ }^{4}$, Mohamad Reza Mahmodi $^{5}$, Kamyar Amraei ${ }^{6}$ and $^{2}$ \\ Asad Mirzaei ${ }^{4}$
}

\author{
${ }^{1}$ Université de Reims Champagne-Ardenne, ANSES, USC Transmission vectorielle et épidémiosurveillance de maladies \\ parasitaires, Université de Reims Champagne-Ardenne, Faculté de Pharmacie, Reims cedex, France; \\ ${ }^{2}$ Parasitology Department, Pasteur Institute of Iran, Tehran, Iran; \\ ${ }^{3}$ Department of Medical Parasitology and Mycology, School of Public Health, Tehran University of Medical Sciences, Tehran, Iran; \\ ${ }^{4}$ Department of Medical Parasitology, Paramedical Faculty, Ilam University of Medical Sciences, Ilam, Iran; \\ ${ }^{5}$ Department of Medical Parasitology, Medical Faculty, Guilan University of Medical Sciences, Guilan, Iran; \\ ${ }^{6}$ Department of Medical Entomology and Vector Control, School of Health, Ahvaz Jundishapur University of Medical Sciences, \\ Ahvaz, Iran
}

\begin{abstract}
Zoonotic cutaneous leishmaniasis (ZCL) is an expanding disease and a public health issue in Iran. In the present study, rate of natural infection of rodent populations with Leishmania was investigated in six endemic foci including 28 villages in Golestan, Esfahan, Yazd, Fars, Khuzestan and Ilam provinces. A total of 593 rodents were captured and identified as Rhombomys opimus $(\mathrm{n}=325)$, Meriones libycus $(\mathrm{n}=171)$, Meriones persicus $(\mathrm{n}=27)$, Tatera indica $(\mathrm{n}=37)$, Nesokia indica $(\mathrm{n}=12)$, Rattus rattus $(\mathrm{n}=13)$ and Mus musculus $(\mathrm{n}=8)$. Microscopic examinations of Giemsa-stained smears showed that 108 out of $593(18.2 \%)$ rodents were infected with Leishmania spp., whereas infection of 186 out of 593 (31.4\%) rodents with Leishmania was then confirmed by ITS1-PCR. The highest rate of infection was found in R. opimus (prevalence of 35\%) and M. libycus (31\%). Based on Restriction Fragment Length Polymorphism (RFLP), 145 (78\%) of 186 samples detected as Leishmania DNA were identified as L. major, $8(4 \%)$ samples as L. turanica and $33(18 \%)$ as mixed infection (L. major and L. turanica). Samples from infected rodents were inoculated subcutaneously at tail base of BALB/c mice. In 35 of them, nodules and ulcers containing amastigotes appeared at the inoculation site. The samples prepared from infected rodents were cultured in NNN medium and only two samples were positive. Rhombomys opimus, M. libycus, M. persicus, $T$. indica and $N$. indica were confirmed as reservoir hosts of ZCL in the studied regions. Leishmania major infection was usually accompanied L. turanica in naturally infected gerbils (R. opimus and M. libycus) in Golestan, Esfahan and Fars provinces.
\end{abstract}

Keywords: Leishmania major, Leishmania turanica, reservoir hosts, rodents, gerbils, PCR-RFLP, Asia

Cutaneous leishmaniasis due to Leishmania major Yakimoff et Schokhor, 1914 is a public health problem in some areas of the Old World (Desjeux 2004). Leishmania major is widely distributed in various populations of rodents in arid and savannah regions (Gramiccia and Gradoni 2005). Rodents play an important role in natural transmission cycle and epidemiology of zoonotic cutaneous leishmaniasis (ZCL), and were already demonstrated as principal vertebrate reservoirs by Hertig et al. (1957).

Rodents belonging to the subfamily Gerbillinae Gray are the main reservoir hosts of ZCL in Iran and other countries, where ZCL due to L. major is endemic (Strelkova 1996, Mohebali et al. 2004, Gramiccia and Gradoni 2005). The disease is endemic in many rural districts of 17 out of 31 provinces of Iran (Yaghoobi-Ershadi 2012).
Identification of the natural hosts of Leishmania Ross, 1903 is crucial to determine the natural cycle of the parasite and to understand the epidemiology of the disease.

In Iran, the first study on the reservoir hosts of cutaneous leishmaniasis was carried out in Turkemen-Sahara region by Ansari and Mofidi (1950) and later by Ansari and Faghih (1953) in Sarakhs district. Several reports indicated occurrence of cutaneous leishmaniasis due to L. major (see Mohebali et al. 2004, Rassi et al. 2006).

Considering the importance of rodents in maintenance of $L$. major in nature, identification of reservoir hosts of the disease is an important step in the control of ZCL. Four important foci of the disease based on rodent reservoir hosts have been reported in Iran: (i) central and north-east of Iran, where Rhombomys opimus Lichtenstein (Rodentia: 


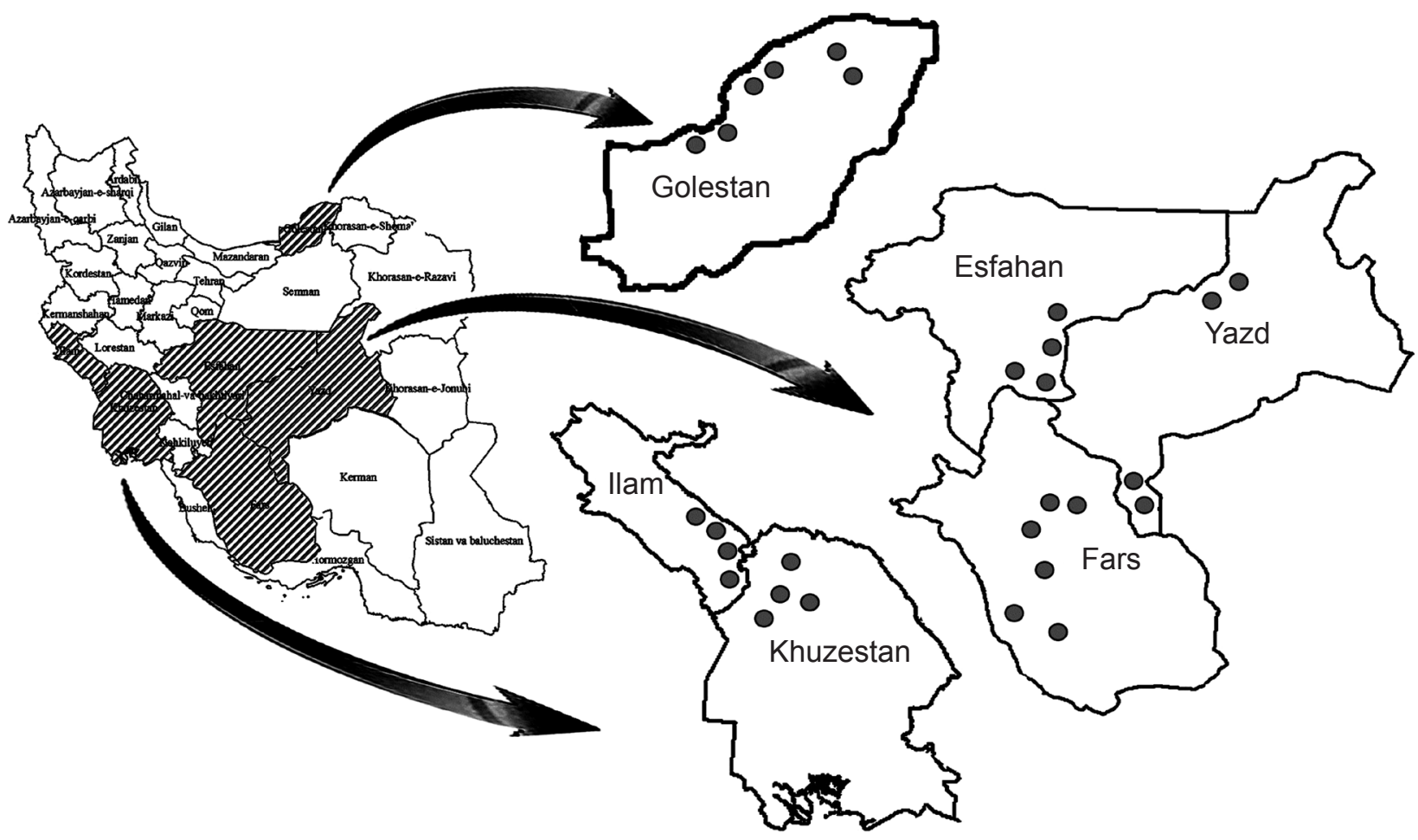

Fig. 1. Sampled rural regions with six endemic foci of zoonotic cutaneous leishmaniasis (ZCL) in Iran.

Gerbillinae) is the main reservoir of the disease (Javadian et al. 1976, Gramiccia and Gradoni 2005, Mirzaei et al. 2011); (ii) west and south-west of Iran, where Tatera indica Hardwicke (Rodentia: Gerbillinae) (Indian jird) replaced $R$. opimus and plays an important role as reservoir (Javadian et al. 1988); (iii) south-eastern Iran, where Meriones hurrianae Jerdon (Rodentia: Gerbillinae) was reported as a natural reservoir host (Kassiri et al. 2011), and (iv) southern Iran, where Meriones libycus erythrourus Lichtenstein (Rodentia: Gerbillinae) is considered the primary and main reservoir host of the disease, whereas $R$. opimus and T. indica are absent (Rassi et al. 2006, 2007).

Rhombomys opimus is reported as the main reservoir host of L. major in the vast territory of the Turan lowland (Central Asia, Afghanistan, Pakistan, Mongolia and some provinces of China) (Strelkova 1996, Shar et al. 2008). In Iran, $R$. opimus is the main reservoir of ZCL in the centre and north-east of the country. Several Leishmania infections due to L. major have been reported from $R$. opimus in endemic and non-endemic foci of ZCL throughout the country (Yaghoobi-Ershadi et al. 1996, 2001, Mohebali et al. 2004, Mirzaei et al. 2011).

Meriones libycus erythrourus is the primary reservoir of ZCL in some areas of the central and southern Iran (Rassi et al. 2001, 2006, 2011a, Moemenbellah-Fard et al. 2003, Mohebali et al. 2004). It has also been found infected in Turkemen-Sahara, Lotfabad and Esfahan, but it was found in localities where only infected $R$. opimus is present (Nadim and Seyedi-Rashti 1971).
Moreover, several investigations have also been carried out into reservoir hosts in other endemic foci of ZCL. Tatera indica, N. indica Gray et Hardwicke (Rodentia: Muridae) and $M$. hurrianae were reported as the main reservoirs infected with $L$. major in the west, south-west and south-east of Iran, respectively (Javadian 1988, Javadian et al. 1988, Yaghoobi-Ershadi et al. 1996, Rassi et al. 2001, Kassiri et al. 2011).

One of the major problems to control ZCL is the lack of information on the dynamics of Leishmania infection in rodent populations serving as reservoir hosts. Therefore, the aim of the present study is to identify the reservoir hosts and to characterize Leishmania infection in rodents in six important foci of ZCL in Iran.

\section{MATERIALS AND METHODS}

The investigation was conducted from August 2008 to October 2011 in 28 villages belonging to provinces of Golestan (Dashboron, Daneshmand, East Ghare Gol, Ozbak Abad, Okhey Tapeh and Shurdegesh), Esfahan (Sajzi, Yelengi, Timiart and Fasaran), Yazd (Tork Abad, Chahak, Chah Afzal and Fath Abad), Fars (Lapoui, Dolat Abad, Gol Dasht, Pol-e-Fasa, Ghir [Band-e-Bast] and Farashband), Khuzestan (Safi Abad, Deh Iji, Ghaale Mokhtar and Ali Abad) and Ilam (Vahdat Abad [Majhin], Badreh, Kolm and Sheikh Makan) (Fig. 1).

They are located in the endemic regions of ZCL in the northeast, centre, south and south-west of Iran with altitude between $580 \mathrm{~m}$ to $900 \mathrm{~m}$. The temperature ranged between $34-40^{\circ} \mathrm{C}$ and the humidity ratio was between $25-55 \%$ during our samplings in the studied areas. 
Active colonies of gerbils in the studied districts were identified and rodents were caught alive using 60 Sherman traps. The traps were placed at gerbil burrows and checked regularly. The identification of the specimens was based on external characteristics: colour, body measurements, ears, tail, feet, teeth, cranium and other specific taxonomic criteria (Boitani and Bartoli 1980, Ziaei 1996).

In the laboratory, the rodents were anesthetized using ether. To confirm infections of rodents, regardless of having any obvious lesions, their ears, tails and the foot pads were examined and impression smears were made (Edrissian et al. 1982). The smears were fixed in methanol, stained with Giemsa and directly examined under a light microscope at high magnification $(1000 \times)$ to search for Leishmania parasites.

Samples from infected rodents were inoculated subcutaneously at the tail base of BALB/c mice. Parasites were also re-isolated from infected mice and cultured in Novy-MacNeal-Nicolle (NNN) culture plus liver infusion broth tryptose (LIT) medium containing $200 \mathrm{IU}$ penicillin per $\mathrm{ml}$, incubated at $20-21^{\circ} \mathrm{C}$ and monitored periodically for Leishmania growth. All positive cultures were subcultured every seven days. Genomic DNA was extracted and purified using a conventional phenol-chloroform protocol (Sambrook and Russel 2001).

All prepared smears from ears, tails and the foot pads of rodents were washed with absolute ethanol to eliminate immersion oil on the smears and covered with $300 \mu$ lysis buffer $(50 \mathrm{mM}$ Nacl, 50 mM Tris, 10 mM EDTA, pH 7.4, 1\% v/v Triton $\mathrm{x}-100$ and $100 \mu \mathrm{g}$ of proteinase $\mathrm{K}$ per $\mathrm{ml}$ in $\mathrm{pH}$ 7.4). After a short time, the smeared material was transferred to a $1.5 \mathrm{ml}$ reaction tube. Then, $15 \mu$ proteinease $\mathrm{K}(20 \mathrm{mg} / \mathrm{ml})$ was added to each tube. Cell lysis was accomplished after incubation for $4-6 \mathrm{~h}$ at $56^{\circ} \mathrm{C}$. The lysate was extracted by phenol-chloroform followed by ethanol precipitation. The DNA was resuspended in $30 \mu \mathrm{TE}$ $1 \mathrm{X}$ and stored at $-20^{\circ} \mathrm{C}$.

Leishmania DNA was amplified by targeting Internal Transcribed Spacer 1 (ITS1) using the primers LITSR (forward: 5'-CTGGATCATTTTCCGATG-3') and L5.8S (reverse: 5'-TGATACCACTTATCGCACTT-3') under conditions described by El Tai et al. (2000) and Schönian et al. (2003). The length of amplicons was about 300-350 bp. Negative and positive controls were used for each batch of PCR. Amplicons were analysed using electrophoresis in agarose gel $1.5 \%$ containing ethidium bromide. HaeIII enzyme was selected with cut site GG $\downarrow C C$ was selected as the best enzyme for RFLP diagnosis was chosen using CLC DNA Workbench 5.2 software (CLC bio A/S, Aarhus, Denmark). Reference strains of L. major (MRHO/IR/75/ER) and L. turanica Strelkova, Peters et Evans, 1990 (MRHO/SU/1983/MARZ-051) were used as control.

Endonuclease digestion was performed in a volume of $30 \mu 1$, which included $10 \mu \mathrm{l}$ of PCR product, $2 \mu \mathrm{l}$ of HaeIII enzyme (Fermentas), $2 \mu \mathrm{l}$ of $10 \times$ buffer and $16 \mu$ of distilled water for four hours at $37^{\circ} \mathrm{C}$ (El Tai et al. 2000, Schönian et al. 2003). Two negative controls were used, one without restriction enzyme and the other with no PCR product. The fragments were analysed using electrophoresis on agarose gel 3\% containing ethidium bromide versus DNA ladder 50 bp (Fermentas). The fragments of $203 \mathrm{bp}$ and $132 \mathrm{bp}$ were observed for L. major. Concerning L. turanica, the expected length fragments of according to the software analysis was 203, 57, 53 and 24 bp. Due to the small size of the fragment of $24 \mathrm{bp}$ and overlapping of two fragments

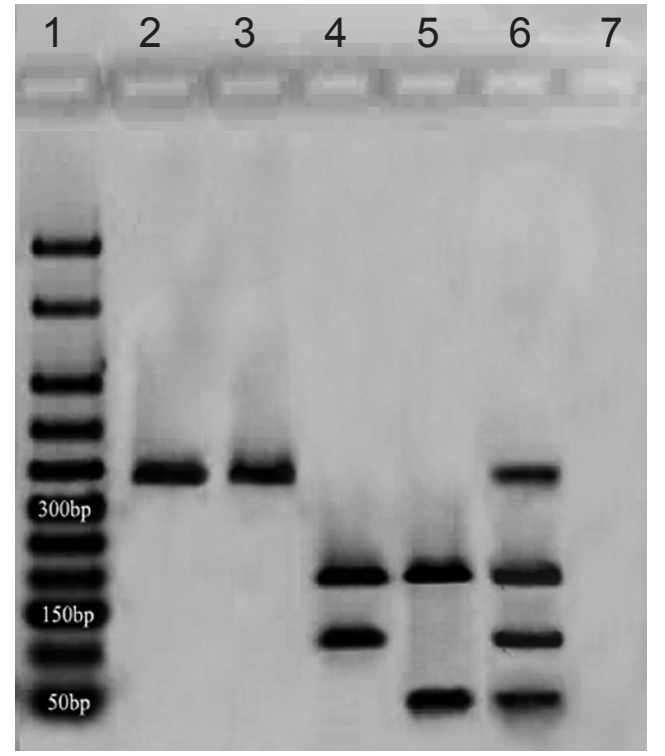

Fig. 2. Ethidium bromide-stained agarose gel of HaeIII digested PCR products of Leishmania species extracted from Giemsastained smears. Lane 1 - molecular marker (50 bp), Lanes 2,3 - undigested L. major and L. turanica; Lanes 4-6-digested L. major, L. turanica and mixed infection (natural co-infection); Lane 7 - negative control.

with a similar molecular weight of $52 \mathrm{bp}$ and $54 \mathrm{bp}$, the observed fragment length on the gel were about $200 \mathrm{bp}$ and $50 \mathrm{bp}$ (Fig. 2). To confirm the results, several PCR products were sequenced directly in both directions using the L5.8S and LITSR primers.

\section{RESULTS}

A total of 593 rodents of seven species, namely Rhombomys opimus (325 samples; i.e. 54.8\%), Meriones libycus (171 samples; 28.8\%), Meriones persicus Blanford (Rodentia: Gerbillinae) (27 samples; 4.5\%), Tatera indica (37 samples; 6.3\%), Nesokia indica (12 samples; 2\%), Rattus rattus Linnaeus (Rodentia: Muridae) (13 samples; $2.2 \%$ ) and Mus musculus Linnaeus (Rodentia: Muridae) (8 samples; 1.4\%), were caught in the present study (Table 1).

Of these, 186 (31.4\%) were positive for Leishmania as detected by ITS1-PCR. Amastigotes were demonstrated in $108(18.2 \%)$ of total smears (Fig. 3), whereas promastigotes in 2 only $(1.1 \%)$ cultured rodent samples. A total of 114 out of $325(35 \%)$ R. opimus and 53 out of 171 (31\%) M. libycus were found to be infected with Leishmania using DNA amplification. No infection was observed in PCR assessments of $R$. rattus and M. musculus (Fig. 4).

Of 186 infected samples, 23 (12.3\%) showed Leishmania spp. infection on one ear and $7(3.7 \%)$ on both ears. The others had no cutaneous leishmaniasis lesion on their ear lobes.

Based on RFLP results, 145(78\% ) of 186 samples detected as Leishmania DNA were identified as L. major, 8 (4\%) samples as L. turanica and 33 (18\%) were 
Table 1. Characterisation of rodent hosts of zoonotic cutaneous leishmaniasis caught in six endemic foci located in the northeast, centre, south and south-west of Iran.

\begin{tabular}{|c|c|c|c|c|c|c|c|}
\hline \multicolumn{2}{|l|}{ Province } & $\begin{array}{l}\frac{\Xi}{ \pm} \\
\frac{0}{0} \\
0 \\
0\end{array}$ & 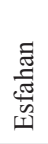 & $\begin{array}{l}\text { ত్ల } \\
\text { స్ర }\end{array}$ & 䒕 & 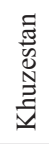 & $\underset{\Xi}{\Xi}$ \\
\hline \multicolumn{2}{|c|}{ Rhombomys opimus } & 227 & 40 & 54 & - & 4 & - \\
\hline \multicolumn{2}{|c|}{ Microscopic (+ve) } & 32 & 4 & 12 & - & - & - \\
\hline \multicolumn{2}{|c|}{ NNN culture (+ve) } & - & - & - & - & - & - \\
\hline \multicolumn{2}{|c|}{ Balb/c inoculation $(+v e)$} & 29 & - & 1 & - & - & - \\
\hline \multirow{3}{*}{$\begin{array}{l}\text { ITS1-5.8C } \\
\text { rRNAgene } \\
(+\mathrm{ve})\end{array}$} & L. major & 59 & 13 & 14 & - & - & - \\
\hline & L. turanica & 8 & - & - & - & - & - \\
\hline & Mix & 14 & 6 & - & - & - & - \\
\hline \multicolumn{2}{|c|}{ Meriones libycus } & 19 & 10 & 10 & 121 & 4 & 7 \\
\hline \multicolumn{2}{|c|}{ Microscopic (+ve) } & 5 & 2 & 2 & 36 & - & - \\
\hline \multicolumn{2}{|c|}{ NNN culture $(+v e)$} & - & - & - & 2 & - & - \\
\hline \multicolumn{2}{|c|}{ Balb/c inoculation $(+v e)$} & - & - & - & 5 & - & - \\
\hline \multirow{3}{*}{$\begin{array}{l}\text { ITS1-5.8C } \\
\text { rRNAgene } \\
(+\mathrm{ve})\end{array}$} & L. major & 7 & 4 & 2 & 27 & - & - \\
\hline & L. turanica & - & - & - & - & - & - \\
\hline & Mix & - & - & - & 13 & - & - \\
\hline \multicolumn{2}{|c|}{ Meriones persicus } & - & - & 2 & 25 & - & - \\
\hline \multicolumn{2}{|c|}{ Microscopic (+ve) } & - & - & - & 7 & - & - \\
\hline \multicolumn{2}{|c|}{ NNN culture (+ve) } & - & - & - & - & - & - \\
\hline \multicolumn{2}{|c|}{ Balb/c inoculation $(+v e)$} & - & - & - & - & - & - \\
\hline \multirow{3}{*}{$\begin{array}{l}\text { ITS1-5.8C } \\
\text { rRNAgene } \\
(+\mathrm{ve})\end{array}$} & L. major & - & - & - & 9 & - & - \\
\hline & L. turanica & - & - & - & - & - & - \\
\hline & Mix & - & - & - & - & - & - \\
\hline \multicolumn{2}{|c|}{ Tatera indica } & - & - & - & - & 19 & 18 \\
\hline \multicolumn{2}{|c|}{ Microscopic (+ve) } & - & - & - & - & 3 & 4 \\
\hline \multicolumn{2}{|c|}{ NNN culture (+ve) } & - & - & - & - & - & - \\
\hline \multicolumn{2}{|c|}{ Balb/c inoculation $(+v e)$} & - & - & - & - & - & - \\
\hline \multirow{3}{*}{$\begin{array}{l}\text { ITS1-5.8C } \\
\text { rRNAgene } \\
(+\mathrm{ve})\end{array}$} & L. major & - & - & - & - & 4 & 5 \\
\hline & L. turanica & - & - & - & - & - & - \\
\hline & Mix & - & - & - & - & - & - \\
\hline \multicolumn{2}{|c|}{ Nesokia indica } & - & - & - & - & 6 & 6 \\
\hline \multicolumn{2}{|c|}{ Microscopic (+ve) } & - & - & - & - & 1 & - \\
\hline \multicolumn{2}{|c|}{ NNN culture (+ve) } & - & - & - & - & - & - \\
\hline \multicolumn{2}{|c|}{ Balb/c inoculation $(+v e)$} & - & - & - & - & - & - \\
\hline \multirow{3}{*}{$\begin{array}{l}\text { ITS1-5.8C } \\
\text { rRNAgene } \\
(+\mathrm{ve})\end{array}$} & L. major & - & - & - & - & 1 & - \\
\hline & L. turanica & - & - & - & - & - & - \\
\hline & Mix & - & - & - & - & - & - \\
\hline
\end{tabular}

mixed infections. Leishmania turanica was found only in $R$. opimus, whereas mixed infections were detected in $R$. opimus and M. libycus. These mixed infections were detected in samples from Golestan, Esfahan and Fars provinces.

The samples prepared from infected rodents were inoculated subcutaneously at the tail base of BALB/c mice. Thirty five of 186 (19\%) mice developed nodules and ulcers containing numerous amastigotes appeared at the site of inoculation 40-50 days after injection.

\section{DISCUSSION}

Distribution of Leishmania major, the causative agent of ZCL, has been found to coincide with Rhombomys opimus (see Strelkova 1996). Therefore, it is important to accurately assess the rate of Leishmania spp. infections in

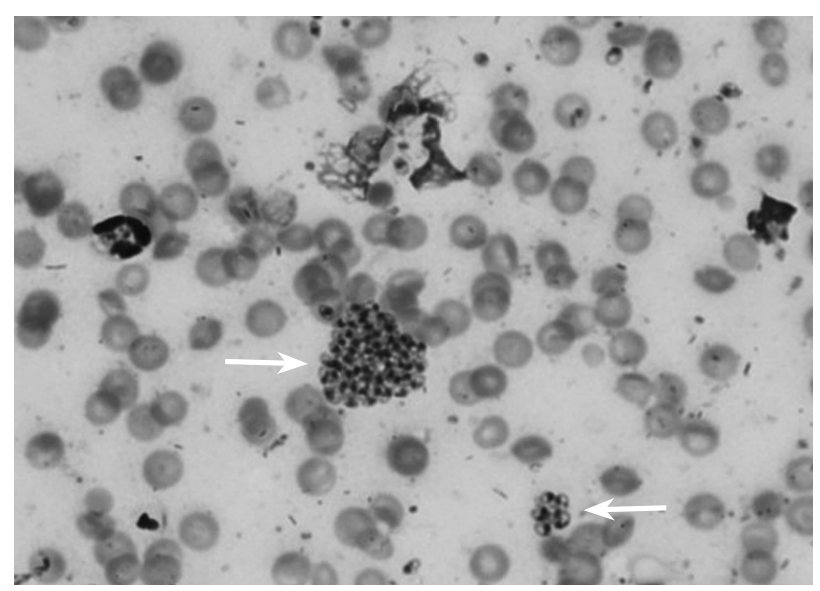

Fig. 3. Giemsa-stained smear prepared from infected Rhombomys opimus, positive for Leishmania amastigotes.

R. opimus and other important rodents that may serve as reservoir hosts.

Rhombomys opimus is the main reservoir host of ZCL in Iran and in some other countries (Javadian et al. 1976, Gramiccia and Gradoni 2005, Mirzaei et al. 2011). In agreement with previous studies, it is the principal reservoir host of ZCL in the central and north-eastern Iran. This great gerbil represented a little more than half (55\%) of rodents caught in the present study. Moreover, 35\% of infected rodents belonged to this species.

The infection of $R$. opimus with $L$. major was previously reported from Kalaleh (37.5\% - Rassi et al. 2008a), Shahroud (91.9\% - Rassi et al. 2008b), Damghan (40\% - Rassi et al. 2011b) and Natanz (55.8\% - Akhavan et al. 2010) counties in Iran. In our study, we have found this gerbil in Golestan, Esfahan, Yazd and Khuzestan provinces. It had been previously reported from Khorasan district, Semnan, Kerman and Sistan va Baluchestan provinces (Nadim and Seyedi-Rashti 1971, Mohebali et al. 2004, Sedaghat and Salahi-Moghadam 2010).

Meriones libycus was the second frequent species (28.8\%), which was caught abundantly in the present study. It was previously found to be infected with Leishmania and can act as a secondary reservoir host in the absence of $R$. opimus in some endemic foci of north-east and centre of the country (Rassi et al. 2007). This role is in agreement with results of this study. Based on our findings, $M$. libycus can be considered an abundant species among rodents caught in Fars province (81.2\%). As many as $33 \%$ of processed M. libycus were infected with L. major in prospected villages in this province. This species also acts as the main reservoir in southern Iran (Rassi et al. 2001, 2006, 2007, Momenbellah-Fard et al. 2003).

Meriones persicus was only caught in two out of six studied foci in the present study, namely in the Yazd and Fars provinces. Nine out of $25(36 \%)$ M. persicus were infected with L. major in Fars province. In fact, this rodent 


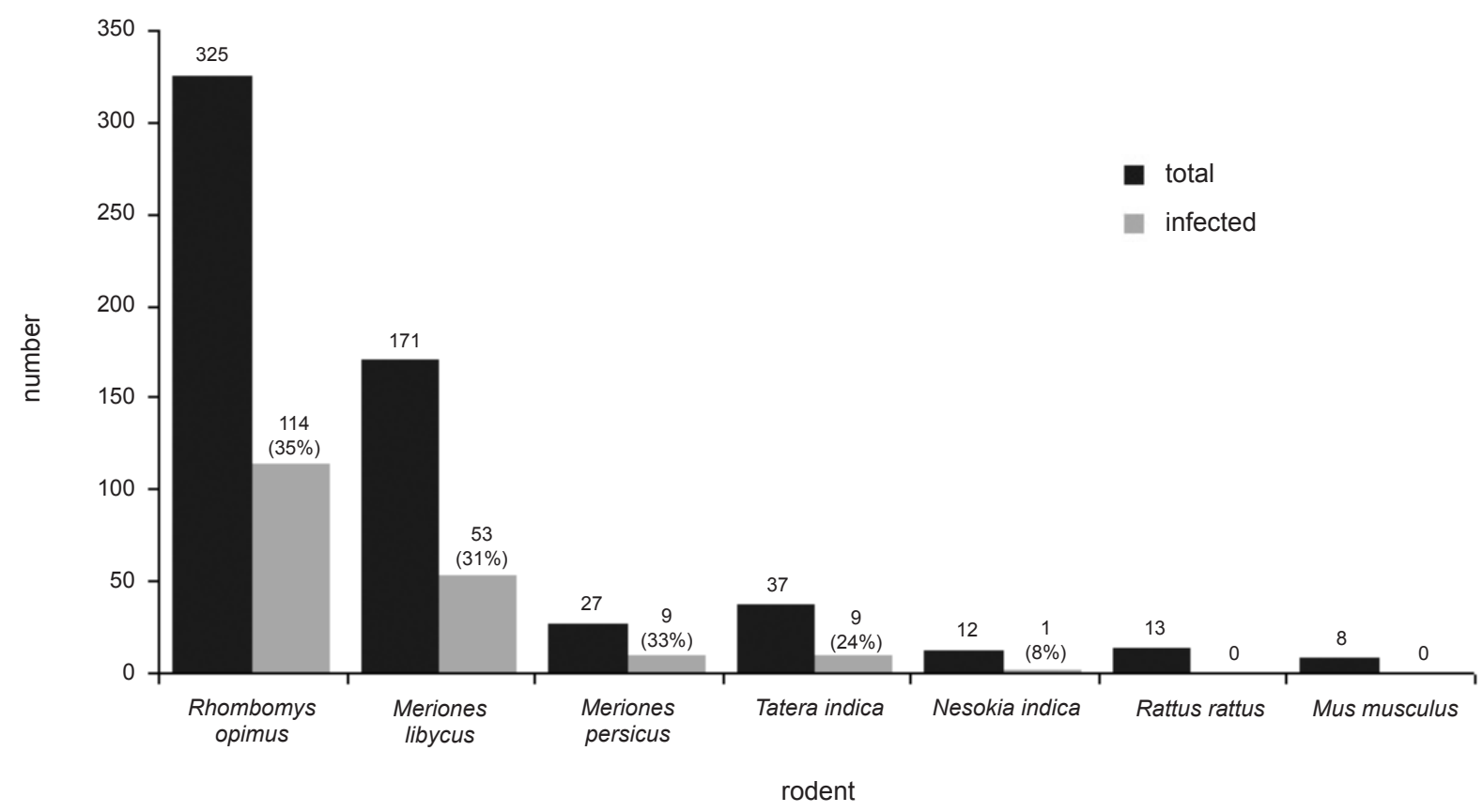

Fig. 4. Graph showing the number of rodent species trapped and infected in the studied counties. Prevalence of infection of individual species of rodents is provided in parentheses.

was previously reported as a probable reservoir of ZCL in Iran (Edrisian et al. 1975).

Tatera indica is the main reservoir host of ZCL in south-western Iran. We found this species in two foci in Khuzestan and Ilam provinces. More than half (54\% and $58 \%$ ) of rodents that we caught in these provinces belonged to $T$. indica and $21 \%$ and $27 \%$ of them were infected with $L$. major, respectively. Our findings are in accordance with previous investigations, which have been carried out in the above mentioned regions (Nadim and Faghih 1968, Javadian et al. 1988, Mohebali et al. 2001).

Nesokia indica has been considered a secondary reservoir in the absence of $T$. indica in south-west of the country (Nadim and Faghih 1968, Javadian et al. 1988, Mohebali et al. 2001). This species represented $18 \%$ (6 out of 33 ) and $19 \%$ (6 out of 31) of rodents captured in Khuzestan and Ilam provinces, respectively. Among processed $N$. indica in these two ZCL foci, one out of $6(17 \%) N$. indica was infected with L. major in Khuzestan province.

In vast territories of Central Asia, mixed infections of wild rodents with L. major (pathogenic to human beings) and L. turanica (non-pathogenic to man) are typical. Leishmania turanica was reported to be the dominant strain in R. opimus populations located in endemic foci of ZCL in Turkmenistan and Uzbekistan (Strelkova et al. 2001).

Based on our findings, it can be assumed that L. major and L. turanica circulate in R. opimus populations of Golestan and Esfahan provinces. Eight out of 88 (9\%) of Leishmania DNA positive samples in PCR-RFLP assessment were identified as L. turanica in Golestan province.
In Esfahan province, no case of L. turanica has been identified in processed $R$. opimus, whereas we found it as a mixed infection with L. major in $32 \%$ of Leishmania DNA positive isolates in our molecular assessment.

In most of the studies, identification of Leishmania species was done after isolation of parasites from culture media, which usually resulted in growth of only one species (Yaghoobi-Ershadi et al. 1996, Mohebali et al. 2004). In Iran, L. turanica was reported from $R$. opimus for the first time by Mohebali et al. (2004). Later, the infection of rodent reservoirs with L. turanica was reported from Kermanshah (Hajjaran et al. 2009), Esfahan (Akhavan et al. 2010) and Damghan (Rassi et al. 2011b) counties. In the present study, L. major infection was accompanied by L. turanica in $20(17.5 \%)$ R. opimus.

The close association of Phlebotomus papatasi Scopoli as the vector of ZCL and infected rodents, e.g. R. opimus, with human population facilitates transmission of the disease. Moreover, urbanization changes in these endemic foci may have contributed to cutaneous leishmaniasis in this concomitant infection. Migration of refugees from Afghanistan and Iraq has also provided suitable conditions for further spreading of the disease in some endemic foci of ZCL in Golestan, Khuzestan and Ilam provinces.

The occurrence of ZCL in some endemic foci, e.g. Golestan, Ilam and Khuzestan provinces, seems to be the result of rapid urbanization, construction of buildings in farms near the colonies of rodents, poor sanitary condition, particularly among populations of illegal immigrants, storage of waste materials around towns, which are suitable for building nests by rodents, etc. Moreover, some 
agricultural projects close to rural houses and existence of some animal shelters among old mud houses together with urbanization changes could increase the number of wild rodents and sand flies to facilitate disease transmission.

In conclusion, this study shows the species composition of rodents that may serve as reservoirs of Leishmania spp. in some regions of Iran. It has also revealed the infection rate of $R$. opimus, M. libycus, M. persicus, T. indica and $N$. indica, which may all serve as the main or secondary reservoirs ZCL in the studied regions. Further ecological and biological studies of rodents, sand flies and human cases in endemic foci of ZCL are necessary to better clarify the circulation of the disease.

Acknowledgments. The authors are grateful to Jerome Depaquit (Reims University - France) for his valuable help. We also gratefully acknowledge Sylvette Gobert for proofreading the manuscript. We thank the staff of health centres of prospected villages in six endemic foci of ZCL in Golestan, Esfahan, Yazd, Fars, Khuzestan and Ilam provinces for their help during the sampling.

\section{REFERENCES}

Akhavan A.A., Yaghoobi-Ershadi M.R., Khamesipour A., Mirhendi H., Alimohammadian M.H., Rassi Y., Arandian M.H., Jafari R., Abdoli H., Shareghi N., Ghanei M., JaLALI-ZAND N. 2010: Dynamics of Leishmania infection rates in Rhombomys opimus (Rodentia: Gerbillinae) population of an endemic focus of zoonotic cutaneous leishmaniasis in Iran. Bull. Soc. Pathol. Exot. 103: 84-89.

AnsARI N., FAGHIH M. 1953: Leishmaniose cutane/L. tropica chez Rhombomys opimus. Ann. Parasitol. Hum. Comp. 25: 24-26.

Ansari N., Mofidi S. 1950: Contribution l'étude des formes humides de leishmaniose cutané. Bull. Soc. Path. Exot. 43: 601607.

Boitani L., Bartoli S. 1980: Macdonald Encyclopedia of Mammals. Macdonald and Co., London, $512 \mathrm{pp}$.

Desjeux P. 2004: Leishmaniasis: current situation and new perspectives. Comp. Immunol. Microbiol. Infect. Dis. 27: 305-318.

Edrissian G.H., Ghorbani M., Tahvildar-Biruni G. 1975: Meriones persicus, another probable reservoir of zoonotic cutaneous leishmaniasis in Iran. Trans. R. Soc. Trop. Med. Hyg. 69: 517-519.

Edrissian G.H., Zovein H., Nadim A. 1982: A simple technique for preparation of smears from the ear of Rhombomys opimus for the detection of leishmaniasis infection. Trans. R. Soc. Trop. Med. Hyg. 76: 706-707.

El Tai N.O., Osman O.F., El Fari M., Presber W., Schönian G. 2000: Genetic heterogeneity of ribosomal internal transcribed spacer (ITS) in clinical samples of Leishmania donovani spotted on filter paper as revealed by single-strand conformation polymorphisms (SSCP) and sequencing. Trans. R. Soc. Trop. Med. Hyg. 94: 1-5.

Gramiccia M., Gradoni L. 2005: The current status of zoonotic leishmaniasis and approaches to disease control. Int. J. Parasitol. 35: 1169-1180.

Hajuaran H., Mohebali M., Alimoradi S., Abaei M.R., EdrisSIAN G.H. 2009: Isolation and characterization of pathogenic Leishmania turanica from Nesokia indica (Rodentia, Muridae) by PCR-RFLP and ITS1 sequencing in Iran. Trans. R. Soc. Trop. Med. Hyg. 103: 1177-1179.

Hertig M., Fairchild E.B., Joinnson C.M. 1957: Leishmaniasis transmission-reservoir project. Ann. Rep. Gorgas. Mem. Lab. 9: 9-11.

Javadian E., Dehestani M., Nadim A., Rassi Y., TahvildareBiruni G.H., Seyedi-Rashti M.A., Shadmehr A. 1988: Confirmation of Tatera indica (Rodentia:Gerbillidae) as the main reservoir host of zoonotic cutaneous leishmaniasis in the west of Iran. Iran. J. Publ. Hlth. 27: 55-60.

Javadian E., Nadim A., Tahvildare-Biruni G.H., Assefi V. 1976: Epidemiology of cutaneaous leishmaniasis in Iran. B:
Khorassanarea, part V; report on a focus of zoonotic cutaneaous leishmaniasis in Esferayen. Bull. Soc. Pathol. Exot. 69: 140-143.

Kassiri H., Javadian E., Abdigoudarzi M. 2011: Natural Leishmania infection in Meriones hurrianae and Tatera indica (Rodentia: Cricetidae: Gerbillinae) in Sistan-Baluchistan Province, South-Eastern of Iran. Adv. Studies Biol. 6: 247-256.

Lichtenstein M. 1823: Beschreibung viele bisher unbekannter Arten von Säugetieren, Vögeln, Amphibien und Fischen. Naturh. Anh. Eversmann's Reiser. 1: 123.

Mirzaei A., Rouhani S., Taherkhani H., Farahmand M., Kazemi B., Hedayati M., Baghaei A., Davari B., Parvizi P. 2011: Isolation and detection of Leishmania species among naturally infected Rhombomys opimus, a reservoir host of zoonotic cutaneous leishmaniasis in Turkemen Sahara, North East of Iran. Exp. Parasitol. 129: 375-380.

Moemenbellah-Fard MD., Kalantari M., Rassi Y., JavadiAN E. 2003: The PCR-based detection of Leishmania major infections in Meriones libycus (Rodentia: Muridae) from southern Iran. Ann. Trop. Med. Parasitol. 97: 811-816.

Mohebali M., Hamzavi Y., Edrissian G.H., Forouzani A. 2001: Sero-epidemiological study of visceral leishmaniasis among humans and animal reservoirs in Bushehr province, Islamic Republic of Iran. East Med. Hlth. J. 7: 912-917.

Mohebali M., Javadian E., Yaghoobi-Ershadi M.R., Akhavan A.A., Hajuaran H., Abaei M.R. 2004: Characterization of Leishmania infection in rodents from endemic areas of the islamic republic of Iran. East Med. Hlth. J. 10: 591-599.

Nadim A., FaGHiH M. 1968: Epidemiology of cutaneous leishmaniasis in the Isfahan province of Iran: I. The reservoir, II. Human infection, Trans. R. Soc. Trop. Med. Hyg. 62: 534-542.

Nadim A., Seyedi-Rashti M.A. 1971: A brief review of the epidemiology of various types of leishmaniasis in Iran. Acta Med. Iran 14: 99-106.

Rassi Y., Abaei M.R., Javadian E., Rafizadeh S., Imamian H., Mohebali M., Fateh M., Hajuaran H., Ismaili K. 2008b: Molecular data on vectors and reservoir hosts of zoonotic cutaneous leishmaniasis in central Iran. Bull. Soc. Pathol. Exot. 101: 425-428.

Rassi Y., Gassemi M.M., Javadian E., Rafizadeh S., MotazeDian H., Vatandoost H. 2007: Vectors and reservoirs of cutaneous leishmaniasis in Marvdasht district, southern Islamic Republic of Iran. East Med. Hlth. J. 13: 686-693.

Rassi Y., Jalali M., Javadian E., Motazedian M. 2001: Confirmation of Meriones libycus (Rodentia, Gerbillidae) as the main reservoir host of zoonotic cutaneous leishmaniasis in Arsanjan, Fars Province, South of Iran (1999-2000). Iranian J. Publ. Hlth. 30: $143-144$. 
Rassi Y., Javadian E., Amin M., Rafizadeh S., Vatandoost H., Motazedian H. 2006: Meriones libycus is the main reservoir of zoonotic cutaneous leishmaniasis in south Islamic Republic of Iran. East Med. Hlth. 12: 475-477.

Rassi Y., Oshaghi M.A., Mohammadi Azni S., Abaei M.R., Rafizadeh S., Mohebali M., Mohtarami F., Zeinali M.K. 2011b: Molecular detection of Leishmania infection due to Leishmania major and Leishmania turanica in the vectors and reservoir host in Iran. Vector-Borne Zoon. Dis. 11: 145-150.

Rassi Y., Saghafipour A., Abaei M.R., Oshaghi M.A., Rafizadeh S., Mohebali M., Yaghoobi-Ershadi M.R., Мohtarami F., Farzin Nia B. 2011a: Phlebotomus papatasi and Meriones libycus as the vector and reservoir host of cutaneous leishmaniasis in Qomrood District, Qom Province, central Iran. Asian Pac. J. Trop. Med. 4: 97-100.

Rassi Y., Sofizadeh A., Abaei M.R., Oshaghi M.A., Rafizadeh S., Mohebali M., Mohtarami F., Salahi R. 2008a: Molecular detection of Leishmania major in the vectors and reservoir hosts of cutaneous leishmaniasis in Kalaleh District, Golestan Province, Iran. Iran. J. Arthropod Borne Dis. 2: 21-27.

SAmbrook J., Russel D.W. 2001: Molecular Cloning. Third Edition. Cold Spring Harbor Laboratory Press, New York, 2344 pp.

Schönian G., Nasereddin A., Dinse N., Schweynoh C., SchalLing H.D., Presber W., JAfFe C. 2003: PCR diagnosis and characterization of Leishmania in local and imported clinical samples. Diag. Microbiol. Infect. 47: 349-458.

Sedaghat M.M., Salahi-Moghadam A. 2010: [Mapping the distribution of the important rodent reservoirs in Iran.] J. Army Univ. Med. Sci. 8: 210-223. (In Persian.)
Shar S., Lkhagvasuren D., Molur S. 2010: Rhombomys opimus. IUCN Red List of Threatened Species - www.iucnredlist. org., $4 / 2010$

Strelkova M.V. 1996: Progress in studies on Central Asian foci of zoonotic cutaneous leishmaniasis: a review. Folia Parasitol. 43: $1-6$.

Strelkova M.V., Eliseev L.N., Ponirovisky E.N., Dergacheva T.L., Annacharyeva D.K., Erokhin P.I., Evans D.A. 2001: Mixed leishmanial infection in Rhombomys opimus: a key to the persistence of Leishmannia major from one transmission season to the next. Ann. Trop. Med. Parasitol. 95: 811-819.

Yaghoobi-Ershadi M.R. 2012: Phlebotomine sand flies (Diptera: Psychodidae) in Iran and their role on Leishmania transmission. J. Arthropod-Borne Dis. 6: 1-17.

Yaghoobi-Ershadi M.R., Akhavan A.A., Mohebali M. 1996: Meriones libycus and Rhombomys opimus (Rodentia: Gerbillidae) are the main reservoir hosts in a new focus of zoonotic cutaneous leishmaniasis in Iran. Trans. R. Soc. Trop. Med. Hyg. 90: 503-504.

Yaghoobi-Ershadi M.R., Hanafi-Bojd A.A., Akhavan A.A., Zahraei-Ramazani A.R., Mohebali M. 2001: Epidemiological study in a new focus of cutaneous leishmaniasis due to Leishmania major in Ardestan town, Central Iran. Acta Trop. 79: 115-121.

Ziaei H. 1996: A field guide for identifying of Iranian desert mamalians. In: Rodents of Iran. Press Association Familiarity with Wildlife. Vol. 1 Iranian Environment Organization. Tehran, pp. 129-187.

Accepted 5 January 2013 